\title{
Geomechanical unit modeling using seismic and well log data in one of the southwestern Iranian oilfields
}

\author{
Mahdi Nazari Sarem $^{1}$ (D) Mohammad Ali Riahi ${ }^{2}$
}

Received: 3 February 2020 / Accepted: 21 July 2020 / Published online: 30 July 2020

(c) The Author(s) 2020

\begin{abstract}
Geomechanical modeling plays a substantial role in the life cycle of a hydrocarbon reservoir and is a key factor in drilling operation optimization. Formations with low mechanical stability can cause wellbore instability or failure during drilling. The main objective of this paper is to predict the elastic parameters (UCS, Young's Modulus, and Poisson's Ratio) at the well and the reservoir volume, using well logs and empirical relationship. The distribution of the elastic parameters in the reservoir is calculated by utilizing geomechanical units (GMUs), which characterize different aspects of the mechanical properties of reservoir and caprocks. The elastic parameters of 30 wells are classified, into five geomechanical units based on the elastic moduli and the mechanical properties of the formations. Each unit is a cluster consisting of Young's modulus, Poisson's ratio, bulk, shear modulus, and UCS. Unit 1 is considered suitable for drilling while maintaining stability, because of its higher values of elastic parameters. Unit 5 possesses the lowest values of predicted elastic parameters. In this study, we also obtain a three-dimensional model of geomechanical parameters for the studied reservoir, using the statistical method.
\end{abstract}

Keywords Elastic parameters · Young's modulus · Poisson's ratio $\cdot$ UCS $\cdot$ Geomechanical units

\section{Introduction}

Nowadays, the importance of geomechanical studies is well known in the life cycle of an oilfield, from hydrocarbon exploration to the drilling stages, and is considered one of the most important tools for increasing production while decreasing the risks involved in the process.

Application of the rock mechanics in different parts of the oil industry in some topics such as sand production, wellbore stability, and optimizing production has played essential role. Proper geomechanical analysis has a main role in identifying and controlling these problems. In Iran, despite the presence of a multitude of problems such as wellbore failures, fault reactivation, sand production, caprock integrity, and gas storage problems, geomechanical studies have

Mohammad Ali Riahi

marahi@ut.ac.ir

Mahdi Nazari Sarem

mah.nazari_sarem@iautcb.ac.ir

1 Faculty of Engineering, Islamic Azad University, Central Tehran Branch, Tehran, Iran

2 Institute of Geophysics, University of Tehran, Tehran, Iran not been considered seriously and its implementation has been limited.

A GMU is a single unit for geomechanical modeling, production planning, and drilling purposes (Faraji et al. 2014). A geomechanical unit can be defined using logs, cores, or could be based upon the judgment (Dusseault 2011). Nygaard (2010) and Uwiera et al. (2011) utilized GMUs as the main component of a geomechanical simulation study for a $\mathrm{CO} 2$ sequestration project and caprock integrity analysis in a proposed SAGD operation, respectively. Adabnezhad et al. (2017) compared different methods of clustering elastic parameters into GMUs and determined that Multi-Resolution Graph-based Clustering (MRGC) results in a more optimized GMU, which is then used for creating a 3D GMU model (Mehrgini et al. 2016). Mousavipour et al. (2020) studied in situ stresses, mud window, and overpressure zone using well logs in a hydrocarbon field.

In this work, a GMU is a set of rock sequences with similar mechanical properties, such as Young's modulus, bulk modulus, shear modulus, Poisson's ratio, and uniaxial compressive strength that have been estimated through simultaneous prestack inversion for the reservoir volume. These elastic parameters are clustered by using MRGC clustering methods to establish the best GMU. The purpose of using 
this method is to determine the distribution of elastic parameters in the reservoir volume.

Rocks with lower mechanical properties, i.e., low uniaxial compressive, high Poisson's ratio, low bulk modulus, and low shear modulus, in shaly lithologies, can lead to many problems, such as well failure during drilling (Eshkalak et al., 2014).

Rocks with high mechanical quality are usually recognized as hard a rock in which most of the caprocks and reservoir units without fractures comprise these types of rocks. So far, various methods for estimating geomechanical parameters in oilfields have been introduced which range from empirical to intelligent methods. In this study, using well $\operatorname{logs}$ (in particular, sonic and density logs) and core data from a well, geomechanical units have been differentiated for 30 wells in one of the southwestern Iranian oilfields.

The main aim of this study is to estimate the elastic parameters (UCS, Young's Modulus, and Poisson's Ratio) using well $\log$ at the well locations and also using prestack inversion and geostatistical approaches to predict these elastic moduli between wells in order to obtain the threedimensional volume of the elastic parameters.

\section{Geological setting}

The Mansouri oil field is located $100 \mathrm{~km}$ north of the Persian Gulf and $50 \mathrm{~km}$ southeast of the Ahwaz City. This study area is situated in the Dezful Embayment that contains the Iranian oilfields in SW of the Zagros. In terms of geology, this oil field is located in the area of Dezful embayment from the northwest of the Ahvaz oil field and the northeast near the Shadegan oil field.

The Mansouri oilfield is located in the south of the Dezful Embayment region, with structural trend same as the Zagros fold-thrust belt. The Mansouri's anticline is elongated with a northwest-southeast trend, which has $30 \mathrm{~km}$ length and $3.5 \mathrm{~km}$ width on the Asmari horizon. Asmari Formation with Eligo-Miocene age is the most important reservoir in hydrocarbon fields. This Formation is the youngest and most important hydrocarbon reservoir in Iran. This formation is composed mainly of the carbonate rocks and is steeply sloping on the deep sediments of the formation. The lower boundary of the Asmari Formation is overlain by the Pabdeh Formation. The Gachsaran Formation is the underlying upper boundary of the Asmari Formation (Motiei 1993; James and Wynd 1965) (Paradigm Co. report, 2006).

The structural trend is similar to adjacent fields such as Ahvaz oilfield and follows the NW-SE trend of the Zagros Mountains. According to the geophysical survey map, the Mansouri structure is extended to $43 \mathrm{~km}$ length and $6 \mathrm{~km}$ width at the top of the Ilam Formation. The northern flank dip of the field is higher than its southern flank, which is $4^{\circ}-5^{\circ}$ in the southern flank and maximum $8^{\circ}$ on its northern flank (Dercourt et al. 1986). The location of the studied field is in the central part of Dezful Embayment, and this is the reason it has a thick pile of Bangestan sequences (Albian-Santonian in age) deposited on shallow marine shelves to deep pelagic basinal settings (Farahzadi et al. 2019).

\section{Methodology}

\section{Uniaxial compressive strength (UCS)}

This parameter indicates the amount of rock strength against pressure and loading, which is obtained by uniaxial compressive strength test, Schmidt hammer, and point load test. In addition, uniaxial test is used to determine this parameter (Goudie 2006). Due to the lack of core data from in the Asmari Formation, an empirical relation by Chang et al. (2006) has been used. Equation (1) estimates the UCS for limestones in the range between 10 and $300 \mathrm{MPa}$.

$\mathrm{UCS}=13.8 E^{0.51}$

\section{Young's modulus}

This modulus is directly measured by the ratio of the longitudinal stress the rock sample to the longitudinal strain resulted from it in the laboratory (Lu 2010).

Using 3D seismic data (Fig. 1) and performing prestack inversion, valuable information such as density, $P$-wave impedance, and shear impedance was extracted from the data.

Using the aforementioned parameters, the necessary elastic moduli (Young's modulus and Poisson's ratio) were successfully determined for the seismic cube. Figure 2 shows Young's modulus cross section, at the position of the well, obtained from seismic inversion.

$E=\frac{\rho V_{S}^{2}\left(3 V_{P}^{2}-4 V_{S}^{2}\right)}{\left(V_{P}^{2}-V_{S}^{2}\right)}$

Zoback (2007) presented a general equation for converting Young's dynamic modulus to static in shaly rock, sandstone, limestone and dolomitic rock using sonic data obtained from 600 core samples:

$E_{\text {static }}=0.018+0.422 E_{\text {dynamic }}$

Figure 3 shows a comparison between the values estimated through inversion (Eq. 2) with the actual values. 


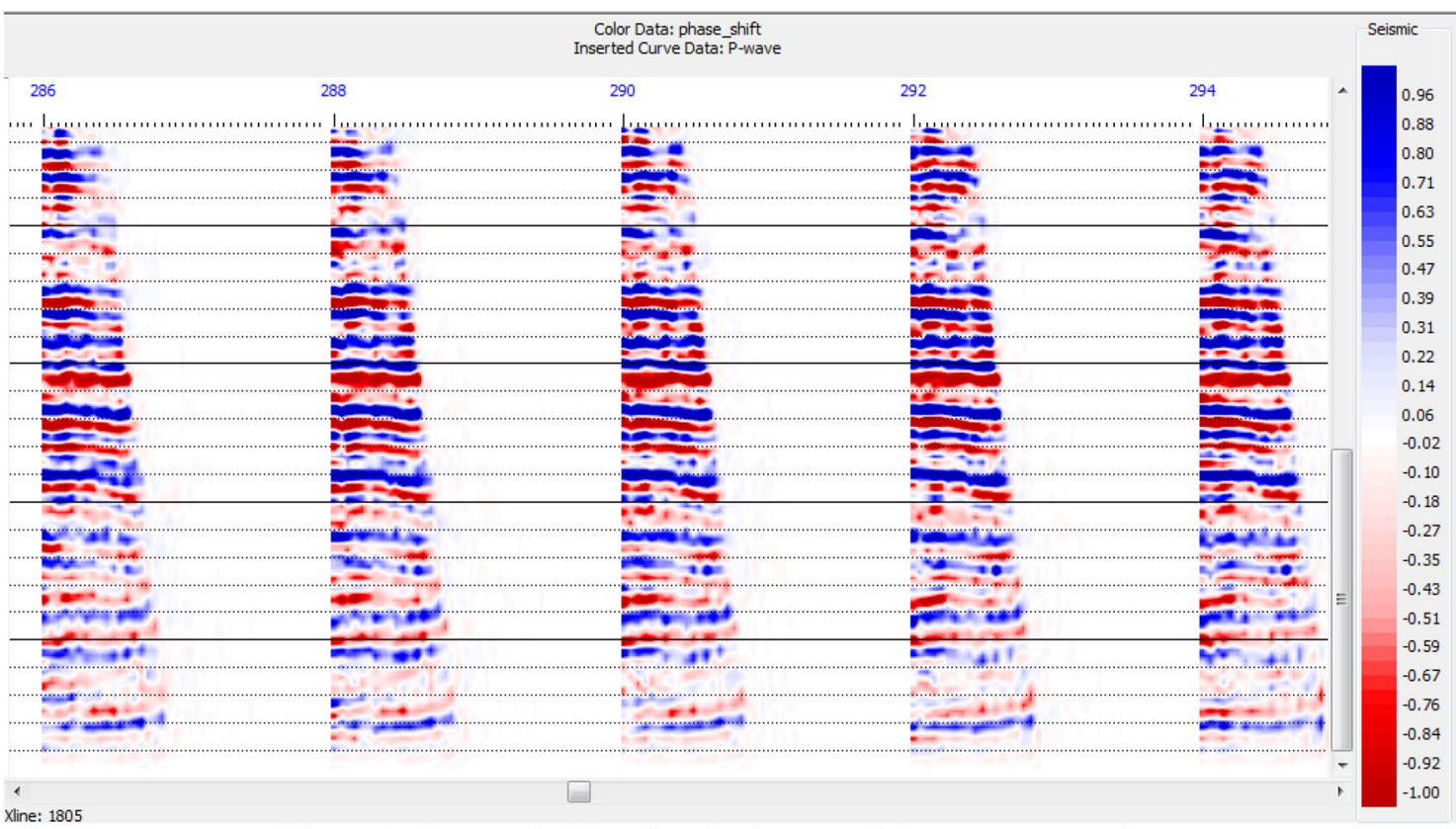

Fig. 1 Prestack 3D seismic data used for the present study

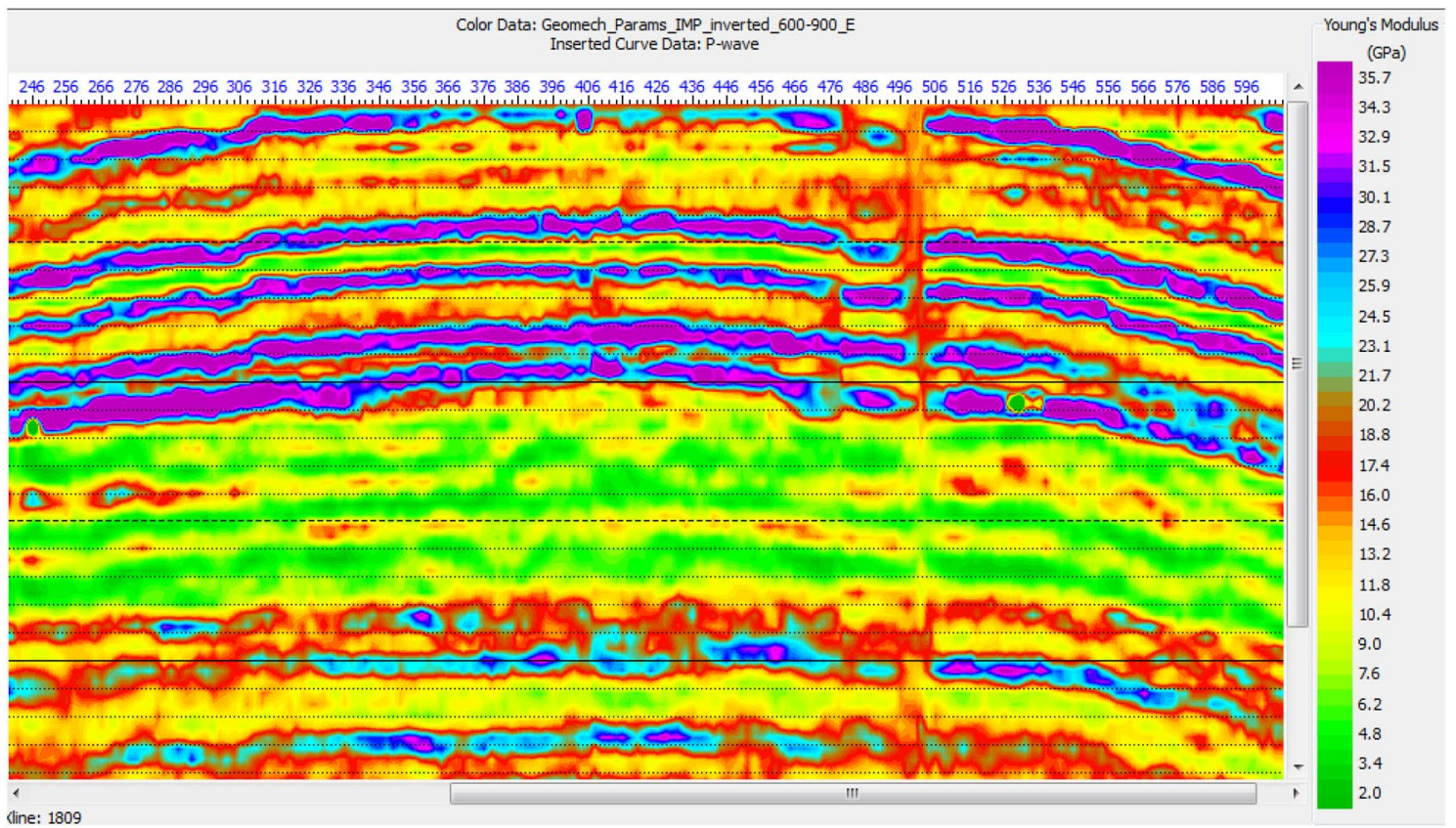

Fig. 2 Dynamic Young's modulus computed through prestack inversion

Equation (3) is used to convert the dynamic Young's modulus into the static form.

\section{Poisson's ratio}

This parameter is the ratio of the lateral strain to the longitudinal strain (Lu 2010), which is estimated through prestack inversion of the 3D seismic data using Eq. (4). Figure 4 shows the Poisson's ratio cross section, at the position of the well, obtained from the seismic inversion.

$$
v=\frac{V_{P}^{2}-2 V_{S}^{2}}{2\left(V_{P}^{2}-V_{S}^{2}\right)}
$$




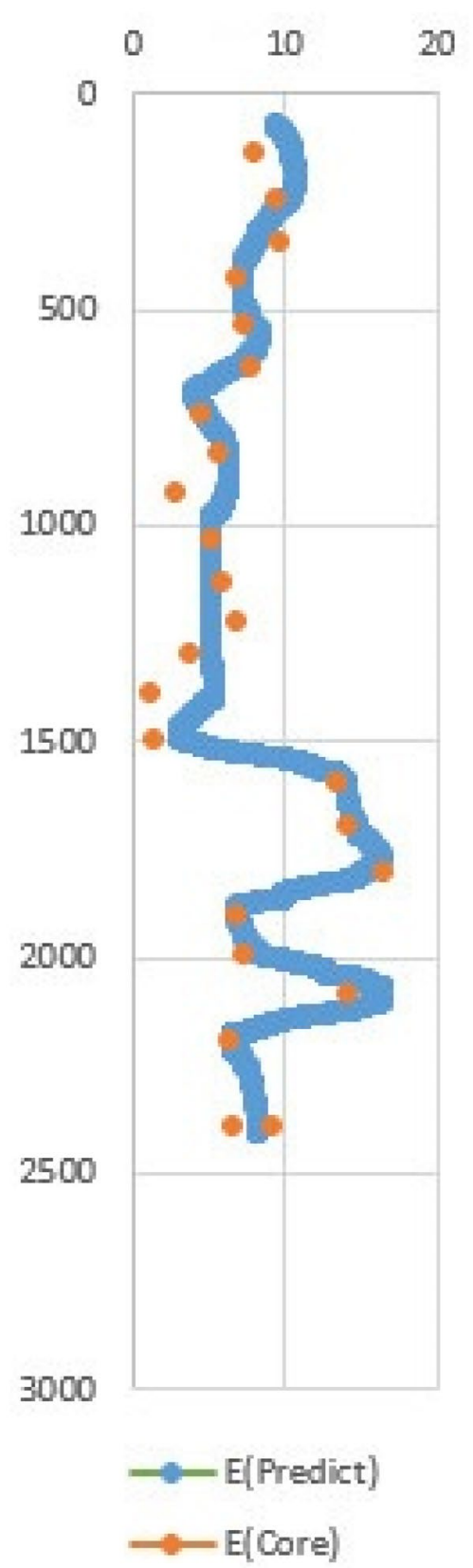

Fig. 3 Comparison between the predicted Young's modulus and Young's modulus obtained from core data. The horizontal axis is in $\mathrm{MPa}$, and vertical axis is in meters

Figure 5 shows how close the graph of Poisson's ratio extracted from seismic data and the Poisson's ratio obtained from the core data follows each other.

\section{Shear modulus}

The shear modulus is indirectly calculated from Eq. (5):
$G=\rho V_{S}^{2}$

Because shear-wave log was only available for one well, using multivariate regression and using sonic $\log \left(V_{p}\right)$, density logs (LLD), gamma-ray logs (GR), a relationship was obtained. The correlation between the shear wave obtained from the multivariable regression and the actual value of the shear wave is about $90 \%$; same relation is also used for other wells (Castagna et al. 1985).

\section{Bulk modulus}

Bulk modulus is indirectly calculated from Eq. (6) through the parameters extracted from the seismic inversion:

$$
K=\rho\left(V_{P}^{2}-\frac{4}{3} V_{S}^{2}\right)
$$

\section{Results and discussion}

\section{Determination of the geomechanical units (GMUs)}

A geomechanical unit is a single unit for the design and modeling purposes. A GMU can be selected from logs, cores, or judgment. Using Eqs. (1)-(6) and using the relationship between compression and shear waves, the geomechanical parameters for different depths using log data were calculated in 30 wells.

Using MATLAB software and utilizing the MRGC method, the number of optimal units or clusters is determined to be five units. Then, data using the MRGC clustering algorithm are clustered into five different geomechanical units. These five units have the largest differences in terms of the predicted parameters (Fig. 6). As shown in this figure, the unit 1 displayed in blue is considered suitable for drilling while maintaining stability, because of its higher values of elastic parameters. The value of all the parameters predicted in the unit 1 is greater than all other units. Unit 5 , which is specified in red, possesses the lowest values of predicted elastic parameters.

In such situations, engineers need to have knowledge of the pore pressure and least principal stress, in order to estimate the optimized mud weight to the stability analyze of the wells.

Because unit 5 has the lowest rock mechanical properties, the geomechanical undesirable rocks (e.g., shaly rocks) and rocks with high fractures and, in general, low strength rocks were classified in this unit. Figure 7 shows a specific depth of well 5 with geomechanical units and GR, caliper, and NPHI logs. It can be seen that in zones where the caliper log shows a fall, geomechanical units are classified as units 4 and 5 . 


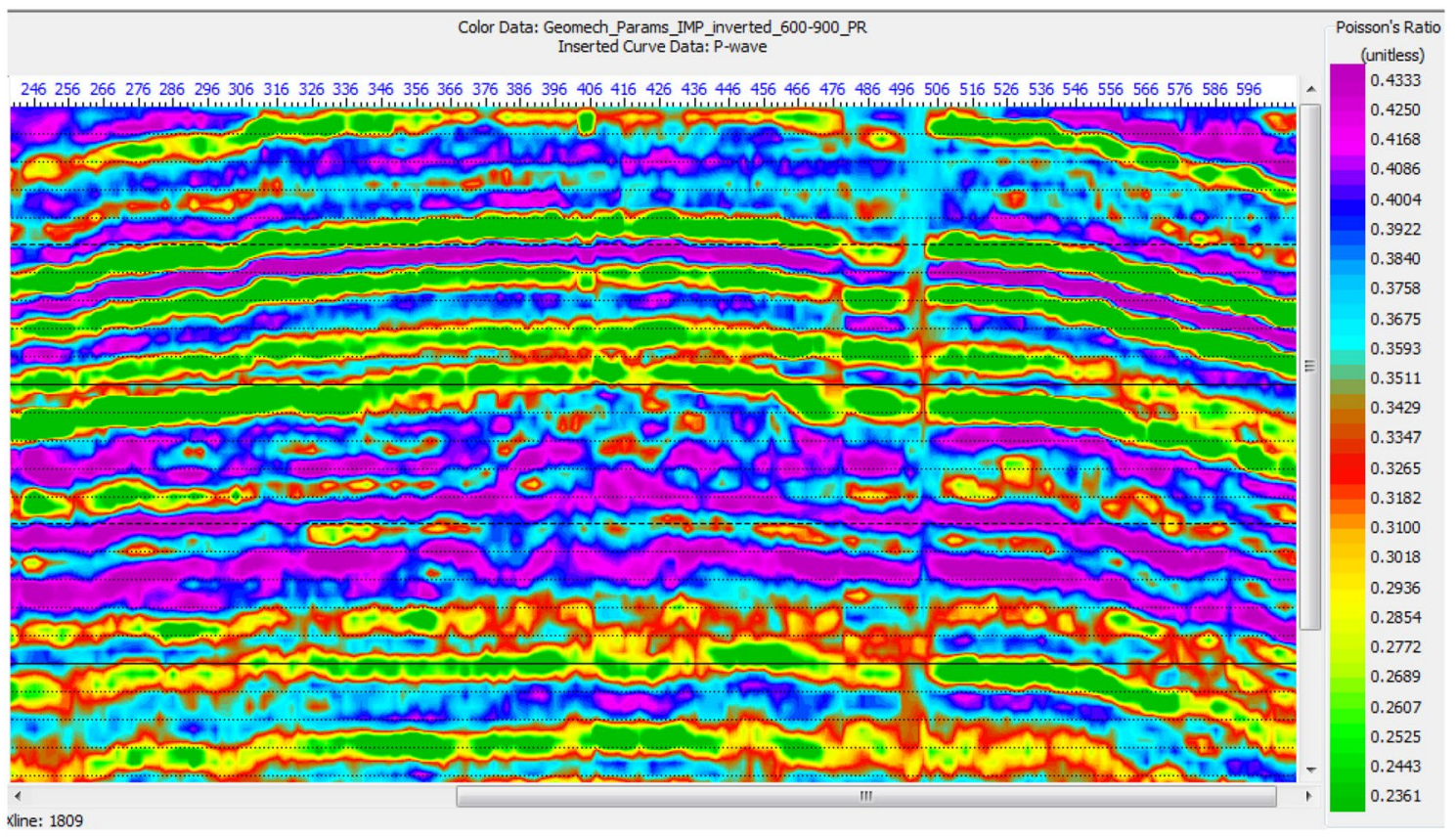

Fig. 4 Poisson's ratio cross section computed through prestack inversion

Figure 8 shows the correlation between geomechanical units in wells 5, 6, 17 and 34 at depths of 2180-2300 m for the oilfield under study. In this figure, Sect. 2 is red in all wells and shows the instability of this section and its continuity in all wells. Zones 3, 4, and 5 due to lower quantities of shaly rocks have low strength.

\section{Geomechanical modeling unit}

After construction of geomechanical units in existing wells, in order to predict geomechanical properties in the entire oilfield, geostatistical methods have been used to build the 3D model of geomechanical units (Fig. 9). SGS is an algorithm which simulates nodes after each other sequentially, subsequently using the simulated values as conditional data. It is necessary to use standard Gaussian values in the SGS method; therefore, the data are transformed into Gaussian space. The basic steps in the SGS algorithm are listed below (Deustch and Journel, 1992):

- Calculate histogram of raw data, and statistical parameters.

- Transform data into Gaussian space.

- Calculate and model variogram of Gaussian data.

- Define a grid.

- Choose a random path.

- Krige a value at each nodes from all other values (known and simulated) and define Gaussian.
- Draw a random value from Gaussian distribution which known as simulated value.

- Simulate other nodes sequentially.

- Back transform simulated value (in this step a realization is generated).

- To generate another realization, steps 1 till 9 are repeated.

Hence, in any point of the oilfield, using geomechanical units we can prevent the occurrence of extensive breakouts and drilling-induced tensile fractures which could lead to wellbore instability. Also, before entering any lithology with different geomechanical properties, we can use the optimized mud weight in evaluating the pore pressure of the formation and the minimum principal stress acting on every 3D model should be validated.

\section{Correlating petrophysical parameters with the GMU}

Based on lithology and porosity changes, the Asmari Formation in this oilfield is divided into eight distinct zones consisting of limestone, sandstone, and claystone. As sandstone layers have high porosity and permeability and low water saturation, most of the oil in the reservoir is trapped in this zone. This classification is based on gamma ray, neutron, density and porosity logs, and petrophysical analysis to determine the well tops. Some of the remarkable characteristics of the Asmari reservoir are as follows: 


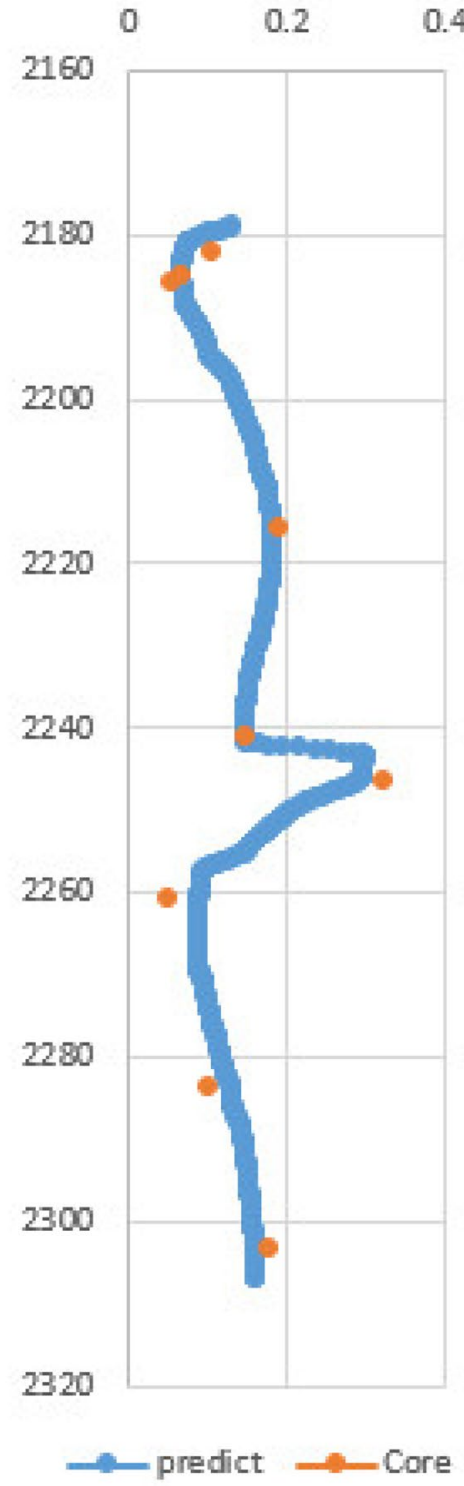

Fig. 5 Comparison between Poisson's ratios obtained from empirical formula and core data
- Zones 1, 6, and 8 are composed of carbonate rocks. Zones 2, 3, 4, and 5 are mainly composed of sandstone facies.

- Zone 1 is made up of dolomite with a significant amount of gypsum. Gypsum has filled most of the existing connections between the pores. Hence, the oil at the migration time may not replace the primary water.

- Zones 2 and 3 are the most important parts of the Asmari reservoir, and most of the produced oil comes from these zones. The porosity percentage of these sections are $28.5 \%$ and $27 \%$, respectively.

- In zone 2 , the porosity percentage in the northern part of the reservoir is better than the southern part, and the low Poisson's ratio of this zone on both sides of the reservoir indicates that potential reservoir quality is better than the middle parts.

- In zone 3, the amount of shale on both sides of the reservoir is higher than the middle part.

The presence of a significant amount of clay minerals, in particular, illite, in the sandstone parts of the oilfield, has reduced the strength of the sandstone zones during drilling operation. In the wells in which caliper log was available, at depths where an abundant amount of clay minerals is present, the caliper log shows washout (Fig. 7). Figure 10 shows the generated Multimin log at Well No. MI 17 of this oilfield. As it is evident in this figure, where the amount of clay minerals has increased in the well, the strength of the dominant lithology has decreased, which is classified in units 4 and 5 as shown in Fig. 10b.

\section{Conclusion}

In this study, we predicted geomechanical units (GMUs) in 30 wells through simultaneous prestack inversion of 3D seismic data and clustered into five units using the MRGC method.

The 3D modeling of geomechanical units makes it possible to assess the mechanical characteristics of the field for drilling purposes, wherever previous discovery

\begin{tabular}{|c|c|c|c|c|c|c|c|c|c|}
\hline & NAME & $\mathrm{COL}$ & PAT & WEIGHT & $E$ & G & k & uCs & v \\
\hline 1 & FACIES_ 1 & & & 645 & & & & & \\
\hline 2 & FACIES_ 2 & & & 459 & & 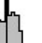 & & & \\
\hline 3 & FACIES_ 3 & & & 449 & & & & & \\
\hline 4 & FACIES_4 & & & 701 & & & & & \\
\hline 5 & FACIES_ 5 & & & 528 & & & & & \\
\hline
\end{tabular}

Fig. 6 Different geomechanical units and differences between the values of the predicted parameters in different units 


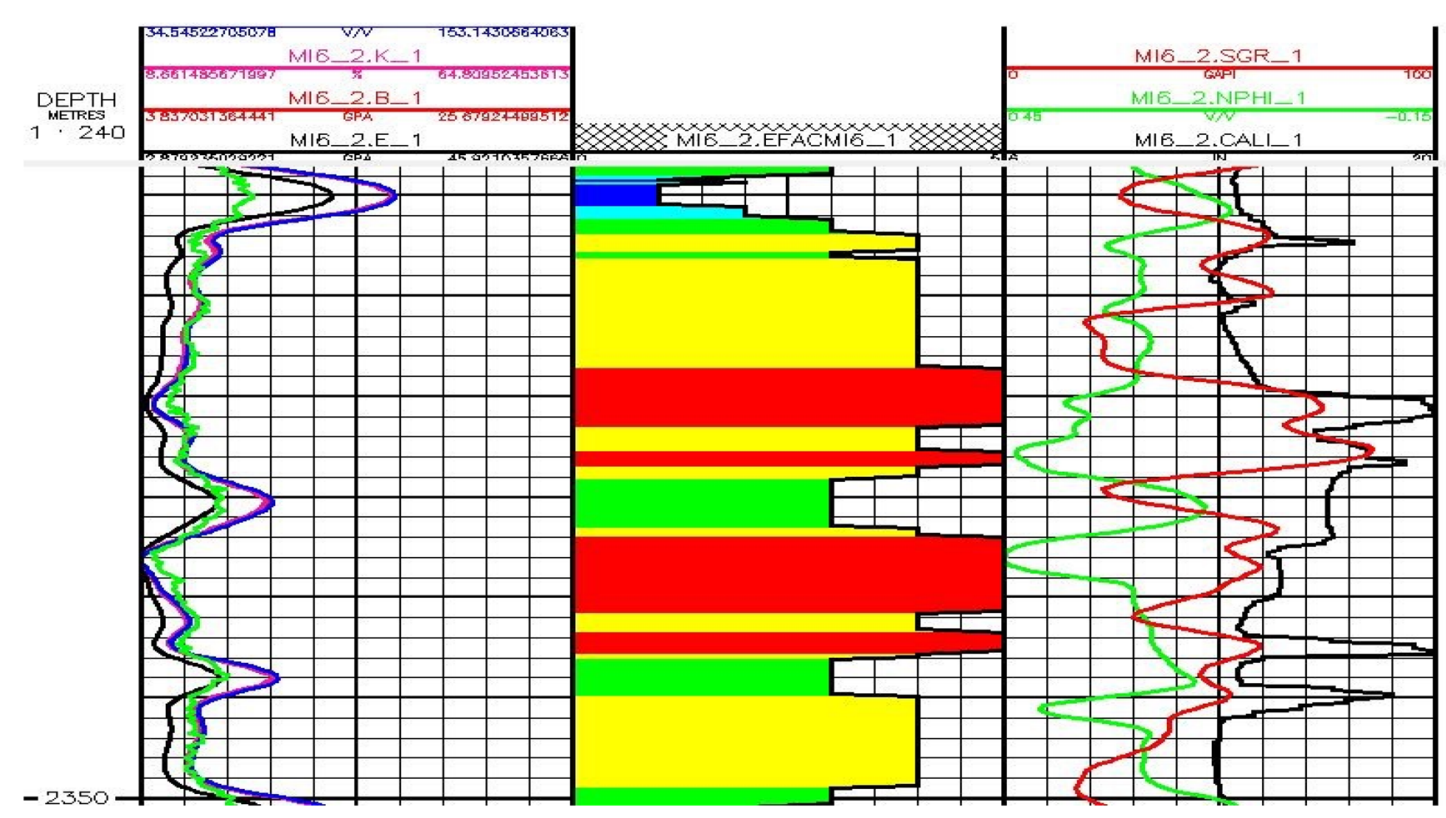

Fig. 7 GMUs, Caliper logs, gamma-ray logs, NPHI log for well 6

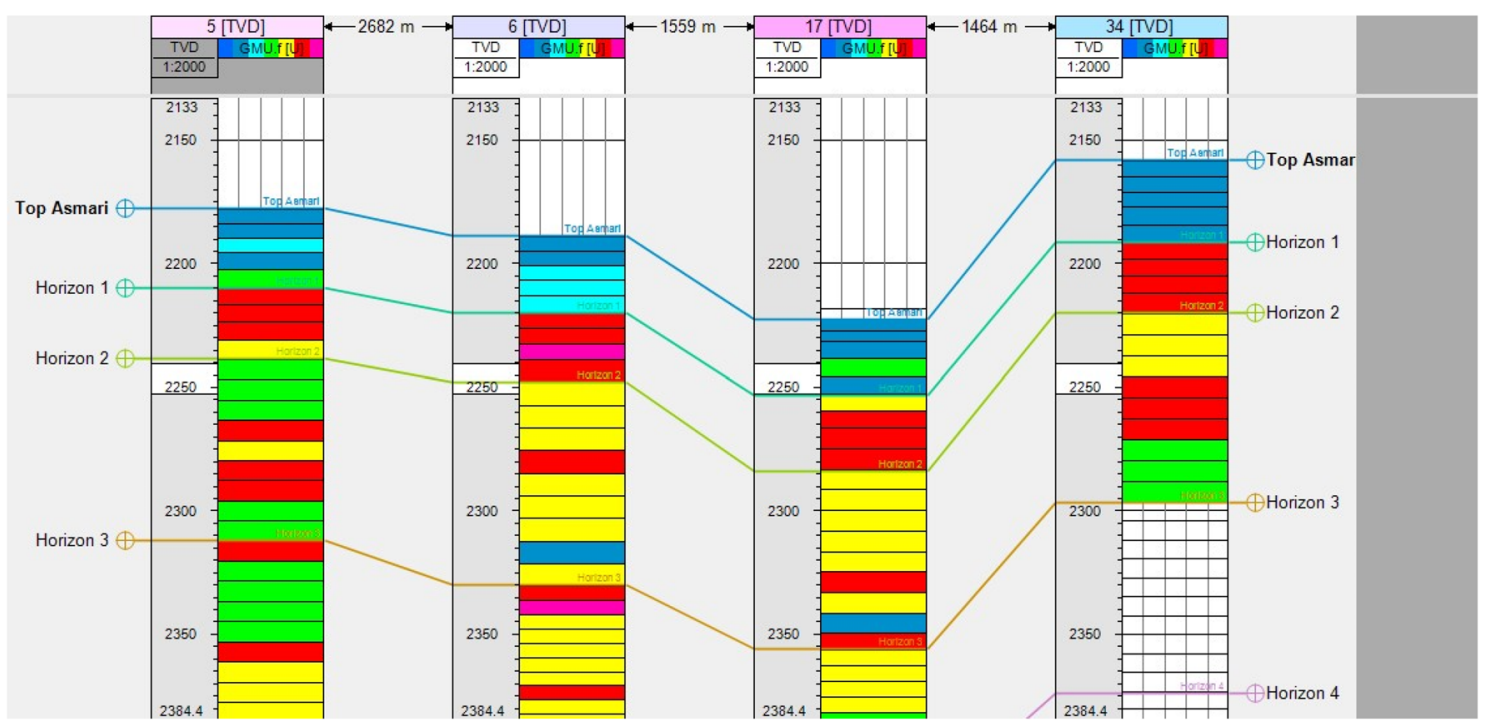

Fig. 8 Geomechanical Unit (GMU) correlation in wells No. 5,6,17 and 34

wells are not available. This 3D model is a crucial step in future evaluations and analysis for potential problems such as fault reactivation, caprock failure, and wellbore in stability.

According to our results and the available geological report of the region, a 3D GMU model is developed, determining that zone 1 has the highest mechanical stability (values of Young's modulus and UCS) due to the absence of large amounts of clay. Therefore, this unit has the least risk of mechanical rock failure and due to higher elastic parameters is the most suitable zone for drilling. Our results for units 4 and 5 were the least promising due to the presence of clay. 


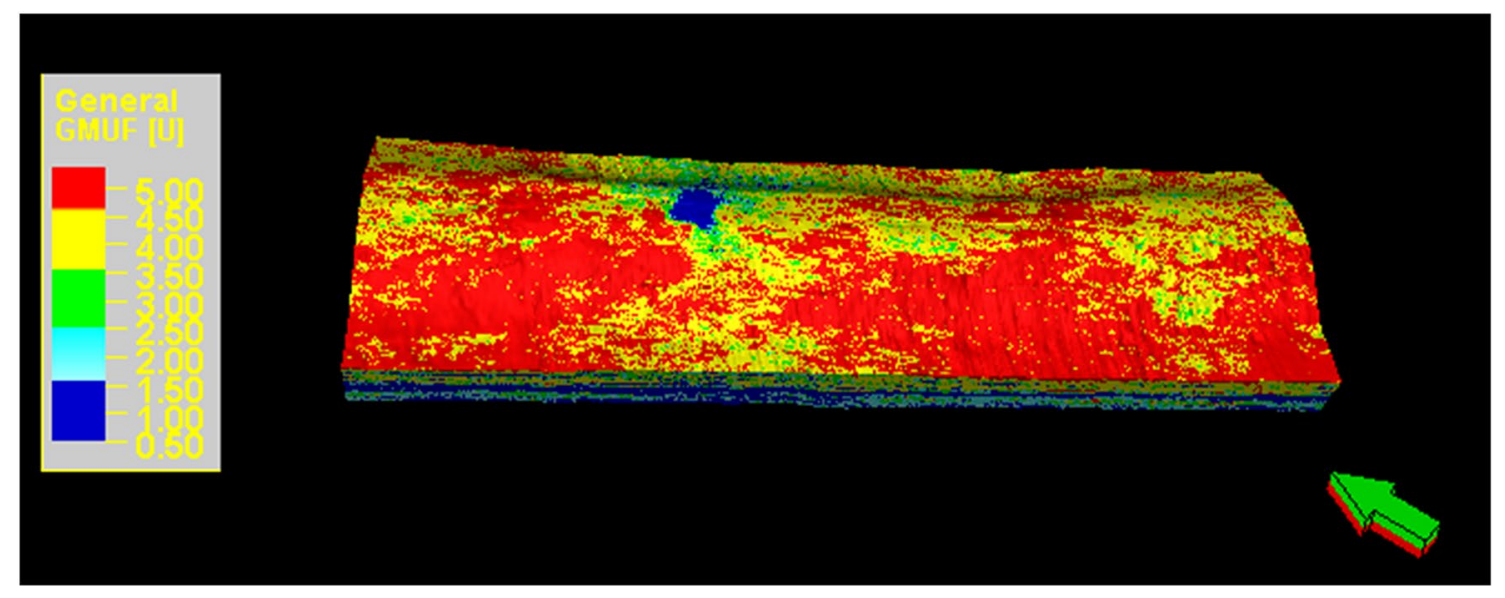

Fig. 9 3D Model of geomechanical units of zone 2 to zone 5

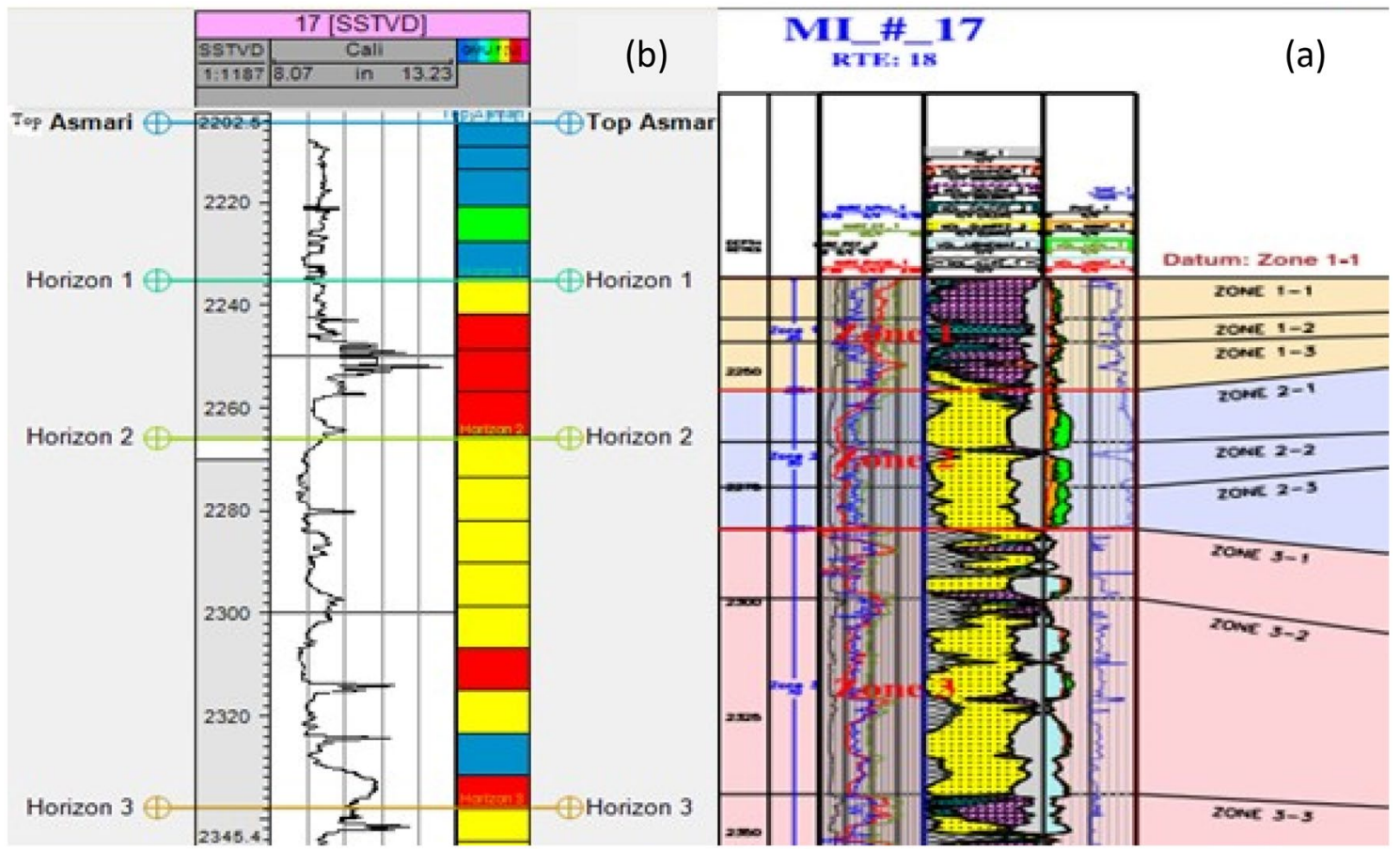

Fig. 10 Comparison between multimin $\log (\mathbf{a})$ and GMU Log (b), which shows the effect of clay minerals in geomechanical units

Acknowledgements This research did not receive any specific grant from funding agencies in the public, commercial, or not-for-profit sectors. The second author would like to acknowledge Research Council of the University of Tehran.

Open Access This article is licensed under a Creative Commons Attribution 4.0 International License, which permits use, sharing, adaptation, distribution and reproduction in any medium or format, as long as you give appropriate credit to the original author(s) and the source, provide a link to the Creative Commons licence, and indicate if changes were made. The images or other third party material in this article are included in the article's Creative Commons licence, unless indicated otherwise in a credit line to the material. If material is not included in the article's Creative Commons licence and your intended use is not permitted by statutory regulation or exceeds the permitted use, you will need to obtain permission directly from the copyright holder. To view a copy of this licence, visit http://creativecommons.org/licenses/by/4.0/.

\section{References}

Adabnezhad P, Aghighi MA, Kadkhodaie A, Rostami A (2017) Threedimensional modeling of geomechanical units using acoustic impedance in one of the gas fields in South of Iran. American Rock Mechanics Association 
Castagna JP, Batzle ML, Eastwood RL (1985) Relationship between compressional-wave and shear-wave velocities in clastic silicate rocks. Geophysics 50(4):571-581

Chang C, Zoback MD, Khaksar A (2006) Empirical relations between rock strength and physical properties in sedimentary rocks. J Petrol Sci Eng 51(3-4):223-237

Dusseault MB (2011) Geomechanical challenges in petroleum reservoir exploitation. KSCE J Civ Eng 15(4):669-678

Eshkalak MO, Mohaghegh SD, Esmaili S (2014) Geomechanical Properties of unconventional shale reservoirs. Hindawi Publ Corp J Petrol Eng. Article ID 961641, 10 pages

Faraji MA, Kadkhodaie A, Shir Mohammadi M (2014) Establishing reservoir Geomechanical Units (GMUs) based on well log data in one of the Persian Gulf oilfields (in Persian), Conference: 8th National Geological Conference of Payame Noor University. Proj Geomech Units Carbonate Rocks. https://doi.org/10.13140 /2.1.4779.0082

Goudie AS (2006) The Schmidt Hammer in geomorphological research. Prog Phys Geogr 30(6):703-718

Lu M (2010) Rock engineering problems related to underground hydrocarbon storage. J Rock Mech Geotech Eng 2(4):289-297. https:// doi.org/10.3724/SP.J.1235.2010.00289
Mousavipour F, Riahi MA, Ghanbarnejad Moghanloo H (2020) Prediction of in situ stresses, mud window and overpressure zone using well logs in South Pars field. J Petrol Explorat Prod Technol. https ://doi.org/10.1007/s13202-020-00890-9

Nygaard R (2010) Geomechanical analysis: Wabamun Area CO2 Sequestration Project (WASP). Energy and Environmental Systems Group, University of Calgary, Calgary

Paradigm (2006), Mansouri field Seismic Interpretation Report, KPE Paradigm

Uwiera M, Carlson M, Walters DA, Palmgren CTS (2011) Geomechanical simulation of caprock performance for a proposed. Low Pressure Steam-Assist Gravity Drain Pilot Proj. https://doi. org/10.2118/148886-MS

Zoback MD (2007) Reservoir geomechanics. Cambridge University Press, Cambridge, pp 42-60

Publisher's Note Springer Nature remains neutral with regard to jurisdictional claims in published maps and institutional affiliations. 